\title{
O código modelo de processo penal para Ibero-América 10 anos depois ${ }^{1}$
}

Ada Pellegrini Grinover

1 - Em 1998, quando o projeto final de Código modelo de Processo Penal para Ibero-América foi apresentado às XI Jornadas Ibero-americanas de Direito Processual, do Rio de Janeiro, a esmagadora maioria dos países dea América Latina adotava a velha lesgislação de características marcadamente inquisitavas, com precedimientos escritos e secretos, as etapas da investigaçăo, da instrução e da sentençã confiadas ao mesmo juiz, a compressão dos direitos de defesa, o sistema probatorio articulado em torno da confissão, a prisão cautelar como regra.

As raríssimas exceçōes eram representadas pelo Código da Província de Córdova, que desde sua promulgação, em 1939, havia instaurado um juízo público, oral, contraditório e contínuo, influindo sobre alguns outros códigos provinciais argentino, denominados "códigos modernos»; pelo Código de Costa Rica, que tinha recpecionado o de Córdoba e pelo Código de Processo Penal unitario do Brasil, de 1940, que abolira os juizados de instrução e adotara uma investigação prévia a cargo da polícia judiciária, como o processo desenvolvendo-se integralmente em contraditorio público.

A postura adotada pelo Código Modelo - cujos estudos havian partido das propostas das V Jornadas Ibero-Americanas de Cartagena (1977), acolhendo as bases de Alcalá-Zamora para o Código de Córdo-

1 Relatório final apresentado após a realização do Congresso Internacional "Processo de integraçāo e solução das controvérsias: do contencioso entre os Estado à tutela individual. Europa e América Latina», Tema: A influência do Código Modelo de Processo Penal na América Latina, Roma, setembro de 1999. 
ba e as bases de Claría-Olmedo e Velez Mariconde para a unificação legislativa em matéria processual penal da América Latina -rompia, portanto, com a tradição anterior amplamente majoritária. E, a partir daí, começaram a disseminar-se as novas tendências do processo penal ibero-americano, configuradas no Código-Tipo da seguinte maneira: a -adoção do modelo acusatório, com a nítida separação das funçôes de acusar, defender e julgar ${ }^{2}$; b - supressão dos juizados de instrução; c atribuição da investigação prévia ao Ministerio Público, com a intervenção do juiz para as medidas cautelares; $\mathrm{d}$ - intransponibilidade para o processo dos elementos probatórios recolhidos na investigação da opinio delicti do Ministério Público; e- processo público e oral, em contraditório; $\mathrm{f}$ - procedimento ordinário, com uma etapa intermédia objetivando receber a acusaçáo; $\mathrm{g}$ - previsão da suspensão condicional do processo (probation); h - existência de procedimientos abreviados; i - supressão, em princípio, da apelação, substituída pelo recurso de cassação e pela revisão pro reo; j- tribunais integrados por elementos do povo; $\mathrm{k}$ - adoção de vários mecanismo de seleção de casos, quebrando o princípio da obrigatoriedad da ação penal; 1 - suspensão do processo em caso de revelia; $m$ - preocupação com a vítima e previsão de acordos reparatórios; n - jurisdicionalização da execução; o - efetivição das garantias do devido processo legal.

2 - Aos poucos, essas idéas forma permeando encontros de estuiosos, eventos e congressos internacionais e nacionais, conferências e debates. O que parecía distante e irreal começou a tornar-se próximo e concreto. A cultura do processo penal estaba mudando. E, sob esse ponto de vista, a influência política do Código Modelo foi notável.

Como se proclamou na Exposição de Motivos, a elaboração de um Código Modelo procurava servir de base a uma impostergável política renovadora, atendendo à imperiosa exigência de estimular um profundo movimento de reforma em todos os países da comunidade hispano-

2 Durante e Congresso, estabeleceu-se um debate entre José Carlos Barbosa Moreira (Brasil) e a Relatora Geral, avenido concordância dos dois no sentido de o modelo acusatório não se confundir como o adversarial system próprio do ordenamento de common law (onde está sendo mitigado), nāo sendo incompatível com iniciativas instrutórias do juiz, após instaurada a açāo penal. Cf, sobre o tema, Ada Pellegrini Grinover, A iniciativa instrutória do juiz no processo penal acusatório, in Rev. Bras. De Ciências Criminais, ed. RT, São Paulo, julho/setembro de 1999, pp. 71-79. 
americana, em grande parte ainda atrellados ao processo penal antigo. E nesse aspecto o Código Modelo atingiu plenamente seus objetivos. Em toda parte começaram os movimientos de reforma. $O$ "modelo acusatório" tornou-se um referencial e ê sintomático que mesmo os países que nāo chegaram a adotá-lo a ele se refiram, considerando-o, bem ou mal, inspirador da reforma.

3 - Se a influência política do Código Modelo é um dado de fato, caracterizando-se como elemento definidor de um novo quadro jurídico-cultural, cumpre sobretudo examinar a influência concreta que tenha porventura exercido no plano técnico-legislativo, é dizer, nas reformas legislativas dos diversos países de América Latina.

É aqui que a influência se matiza em diversas nuances, que serão analisadas nos novos códigos e projetos, de alguna forma ligados ao Código Modelo. O estudo será feito a partir de uma posição ambígua que se encontra em evolução, como a da Argentina; passando por uma incapacidade de superação da tensão entre o velho e o novo, como na Colômbia e no projeto do Uruguai; tramitando por reformas pontuais, como no Brasil; e chegando à adoção do modelo acusatório do Código Tipo, con na Guatemala, Costa Rica, El Salvador, Paraguai (códigos já em vigor), na Venezuela, na Bolívia e no Peru (códigos promulgados, más ainda não vigentes), no projeto do Chile e, ao que se sabe, em Honduras e no Equador.

3.1. A Argentina, nas palavras do relator nacional ${ }^{3}$, assumiu posição ambígua com relação ao Código Modelo. Pátria de Julio maier, principal artífice da última versão do Código, rica de antecedentes promissores - como o Código de Córdoba e os «códigos modernos» o país incorporou as idéias do novo processo acusatório em alguns códigos provinciais (Tucumã, Santiago del Estero) mas não de forma generalizada: o Código de Processo Penal da Nação (1991) e moldado no Projeto Ricardo Levene, guardando os juizados de instrução. O da Província de Santa Fé (1993) invoca o Código Modelo mas adota um procedimento misto. $\mathrm{O}$ mais novo código, da Província de Buenos Aíres (1998), incorpora mais francamente o sistema acusatório, extinguindo os juizados de instrução, más não avança, por exemplo, em relação à etapa intermedia.

3 Pedro Juan Bertolino 
Se deja como for, nuna visão macroscópica, pode-se afirmar que os direitos do acusado são preservados e, mesmo quando mantida a fase de instruçăo formal, os novos processos a abrem a uma participação das partes, tentando fugir do modelo inquisitório e secreto anterior.

Deve-se dizer, contudo, que a adoção do Código Modelo está em franca evoluçăo.

Diversos projetos de códigos provinciais acolhem as linhas mestras do Código Tipo, com a abolição dos juizados de instrução e a previsão de um juízo todo público e oral. Passa-se a enumerá-los, de acordo com relatório solicitado após a realização do Congresso de Roma ${ }^{4}$ :

a. Província de Neuquén (Projeto Mayer e Binder): investigação a cargo do Minsterério Público, reforço das garantias processuais, critérios de oportunidade, maiores poderes processuais à vítima, participação do imputado na investigação preparatória, etapa intermediária no procedimento ordinário, acordos reparatórios, juízos abreviados, impugnaçōes reservadas ao arquivamento e à sentença final.

b. Província de Chaco (lei promulgada a 6.7.99, para entrar em vigor em janeiro de 2001): Investigaçăo preparatória e exercício da açõ penal pelo Ministério Público, preocupação com a vítima, medidas cautelares exclusivas do juiz de garantías, previsão do recurso por inconstitucionalidade, cassação e revisão contra a sentença, juízos abreviados.

c. Província de Catamarca (lei próxima a ser sancionada): investigação preparatória a cargo do Ministério Público com monopólio das medidas cautelares ao juiz; juizo abreviado em caso de flagrante, suspensão condicional do processo, recurso de cassação amplo, preocupaçăo com a vítima.

d. Província de Entre Rios (projeto em discussāo): investigaçāo prévia atribuída ao Ministério Público, ampla legitimação à vítima (individual ou coletiva), tribunal de jurados, medidas cautelares a cargo do juiz, podendo o Ministério Público autorizar a liberdade do acusado.

e. Província de Mendoza (3 projetos em discussão): seguem-se as linhas gerais do Código de Costa Rica 5 .

4 Relatora Angela Ledesma.

5 Ver infra, n. 3.4. 
Observe-se que em todos os projetos dos códigos provinciais argentinos, a iniciativa instrutória do juiz, no processo, é bastante limitada, contrariando a linha de raciocínio desenvolvida na nota n.2.

Finalmente, cumpre notar que a evolução rumo ao modelo do Código Tipo se faz, na Argentina, também no projeto do Executivo de reforma do Código da Nação, em que a investigação prévia ficará a cargo do Ministério Público, o imputado poderá acompanhá-la desde o início, a vítima deverá ser consultada para que o MP aplique o princípio da oportunidade e terá poderes processuais, as medidas cautelares serão exclusivas do juiz, está previsto o procedimento intermédio e a cassação será ampla ${ }^{6}$.

3.2. A tensão entre o velho e o novo fica patente no Código da Colômbia (1991) e no projeto do Uruguai, que deverá entrar em vigor em fevereiro de 2,000.

O sistema colombiano" é misto e, embora se fale em "tendência acusatória", o que ocorreu foi simplesmente a substituição do juiz instrutor pelo Ministerio Público, o qual integra o Poder Judiciário. A instrutória formal é por ele dirigida, e ele dirigida, e é ele quem investiga e quem determina os provimentos cautelares. A polícia judiciária atua exclusvamente por ordem do Ministério Público. Faculta-se ao imputado a contrariedade das provas, e todas as provas da investigação e da instrução são permanentes e eficazes.

Como pontos positivos, pode-se salientar o contraditório no juizado de instrução e a reserva ao juiz da função de julgar. Mas a atribuição ao mesmo órgão (Ministério Público) da tarefa de investigar, de valorar a prova e de autorizar as medidas cautelares é de indole tipicamente inquisitiva.

No Uruguai ${ }^{8}$, o projeto aprovado pelo Congresso substituiu outro, apresentado pela Corte Suprema e pelo Instituto Uruguaio de Direito Processual, que se aproximava a mais do Código Modelo, más que mesmo assim conservara a instrutória formal, em contraditorio, a cargo do Ministério Público.

\footnotetext{
6 Relatora Angela Ledesma.

7 Relator, Jairo Parra Quijano.

8 Relator, Jaime Greif.
} 
$\mathrm{O}$ atual projeto mantém-se fiel ao sistema misto. Sua única aproximidade com o Código Modelo está na oralidade, publicidade e bilateralidade .

3.3. O Brasil encontrava-se em situação peculiar, quando da apresentação do Código Modelo. Desde o Código de 1940, já adotava o processo de estrutura acusatória, sem juizados de instrução, com uma fase de investigação prévia, atribuída à polícia judiciária, medidas cautelares ordenadas pelo juiz, acusação formulada pelo Ministério Público, procedimiento público e contraditório. Más o estatuto processual, até a Constituição de 1988, guardava alguns resquícios do sistema inquisitivo: certos procedimientos instaurados ex officio ou pela polícia, para as contravenções penais e as lesões corporais culposas, inquérito policial sigiloso, buscas e apreensōes com mandado policial, prisão cautelar obrigatório até 1977, garantías ao acusado restritas ao contraditóio e ao direito de defesa.

Foi a constituição que assinalou para o processo penal a marca indefectível do modelo acusatório. E, como observa o relator brasileiro? embora não se possa dizer que o texto do Código Modelo, contemporâneo à Constituição, tenha influído sobre esta, é inegável que seu ideário permeou a Lei Maior, até pela identidade de alguns juristas que colaboraram na produção de ambos.

Assim, a ação penal pública ficou privativa do Ministério Público e privativa do juiz ficou a função de determinar qualquer providência cautelar. A polícia judiciária continuou encarregada das investigaçōes prévias, mas ao Ministério Público (autônomo e desligado do Judiciário e do executivo) coube o controle externo da polícia, bem como poderes relacionados com a atividade investigativa. Outra aproximação como o Código Modelo ocorreu pela admissão da transação penal, em nível constitucional. Novas garantias foram introduzidas, como a publicidade dos atos processuais, o direito ao silêncio, a proibição das provas obtidas or meios ilícitos, a extensão do contraditório ao processo administrativo.

No campo legislativo, a influência direta do Código Modelo manifestou-se pela reestructuração do instituto da revelía, modificado em 1996 e agora limitado à circunstância de o acusado, citado pressoalmente, não comparecer ou abandonar o processo. Más, na citação ditalícia, se o acusado não comparecer ou não constituir

9 Antônio Scarance Fernandes. 
advogado, o processo e o prazo prescricional ficam suspensos, podendo o juiz determinar a produção antecipada de provas consideradas urgentes e, se for o caso, decretar a prisão preventiva, restrita aos casos de necessidade previstos no Código de Processo Penal. E, embora em lei sucessiva, de 1998, ficasse consignado que a suspensão do processo à revelia não ocorreria nos crimes de "lavagem de dinheiro", a doutrina está entendendo que a exceção só diz respeito às medidas cautelares de aprensão.

Além disso, no campo da justiça penal consensual, a lei de 1995 não só regulou a transação prevista na Constituição, más tambén criou o acordo reparatório e a suspensão condicional do processo (probation). E, posteriormente, a tansação penal foi ampliada pelo Código de Trânsito, de 1997 e pela Lei dos crimes contra o ambiente, de 1998, a qual tambén reforçou os acordos reparatóios. Cumpre observar que, no sistema brasileiro, a transação penal e a suspensão condicional do processo não pressupōem o reconhecimento de culpabilidade do imputado e que o acordo civil, em alguns casos, é causa de extinção da ação penal.

O Ministério Público, por sua vez, avançou no caminho de uma ingerência mais direta nas investigaçóes policiais, por intermédio de suas leis orgânicas, que fixaram formas de controle e lhe permitiram maior atuação nessa fase da persecução.

No plano estrutural, projetos de leis foram apresentados visando a um melhor tratatamento da investigação prévia e a generalizar a previsão de uma fase intermédia no procedimento ordinário, destinada ao juízo de admissibilidade da acusação, hoje confina aos processo afetos ao Tribunal do Júri (competente para os crimes dolosos contra a vida, consumados ou tentados, e crimes conexos), bem como aos relativos aos crimes praticados por funcionários públicos.

Como nota destoante no quadro da influência do Código Modelo, uma lei de 1995, que trata do cirme organizado, atribuiu ao juiz, na fase prévia, a facultade de efetuar pessoalmente as investiga es, de forma sigilosa, contrariando toda a tradição do direito brasileiro a tal ponto, que os juízes não têm utilizado os poderes legais.

Por último, cabe assinalar que as novas tendências do processo penal, moldadas pelo Código Modelo, são objeto de constantes estudos e debates, devendo desaguar, mais cedo ou mais tarde, em mudanças legislativas. 
3.4. A adoçẫo do modelo acusatorio do Código Tipo rompeu com a estrutura anterior na Guatemala, Costa Rica, El Salvador, Paraguai (códigos já em vigor), na Venezuela, na Bolívia e no Peru (códigos promulgados, mas ainda não vigentes), no projeto do Chile e, ao que se sabe, em Honduras e no Equador.

O primeiro código nacional a introduzir o sistema do Código Modelo foi o da Guatemala, por influ ncia direta de Julio Maier e Alfredo Binder, da Argentina, nos trabalhos de preparação ${ }^{10}$. Sancionado em 1992, entrou em vigor em 1994, prevendo a investigação prévia a cargo do Ministério Público, com a atribuição ao juiz das medidas cautelares. O procedimento comum contempla a fase intermédia e estão regulados o procedimento abreviado e os acordos reparatórios. Há vários critérios de oportunidade de ação penal, com consentimento judicial e, na maioria dos casos, com anuência da vítima. A suspensão do processo (probation) depende da reparação do dano. Foi mantida a apelação de não estão previstos tribunais populares.

Costa Rica, que já adotava um procedimento público e oral, em instância única, por recepção do Código de Córdoba de 1939 , incorporou no novo Código Promulgado em 1996 e em vigor desde 1998) o sistema e a estrutura do Código Modelo ${ }^{11}$. Suas características são as enunciadas para o Código da Guatemala, com as seguintes modificações, que o aproximam ainda mais do Código Tipo: um melhor tratamento da fase intermédia do procedimento ordinário e um juízo público mais acusatório; e, com o princípio da oportunidade, um novo método de extinção da ação penal para alguns delitos, por força da conciliação integral do dano. O juízo mantém-se em instância única, com a sentença impugnável pela via da cassação ou revisão.

O Código de El Salvador, promulgado em 1996, entrou em vigor em $1998^{12}$. Acompanhando o modelo do Código Tipo, aproxima-se bastante deste pela previsão de tribunais populares como regra geral. Aliás, mesmo quando o procedimento penal era escrito, existiam jurados em El Salvador, mas o Ministério Público e a defesa limitavan-se a argumentar na base das provas escritas, que não eram produzidas perante o Júri. Hoje todo o processo é público, oral e contínuo e se

10 Relator, Julio Maier.

11 Relator, Julio Maier.

12 Relator, Julio Maier. 
desenvolve numa única instância, sendo a sentença impugnável pela via de cassação e da revisão.

O novo Código do Paraguai, promulgado em 1998, entro em vigor em julho de $1999^{13}$. O Ministério Público dirige a investigação, com o auxilio da polícia judiciária sobre a qual exerce poder disciplinar, e promove a ação penal pública. As medidas de conteúdo jurisdiccional são privativas do juiz. O procedimento ordinário, após a etapa preparatória, passa pela etapa intermédia, chegando à de julgamento, oral e público, or um tribunal colegiado. O Código tambén prev procedimentos abreviados e a execução é jurisdicionalizada.

Existem, finalmente, vários códigos já promulgados, mas ainda não em vigor.

A análise do Código da Venezuela, promulgado em 1998, más cuja vacatio legis foi prorrogada, aponta ter ele ficado a meio caminho entre o de Costa Rica (o mais fiel ao Código Modelo) e o da Guatemala. Conforme observa a relatora $\left({ }^{14}\right)$, além da supressão dos juizados de instrução, substituídos pela investigaçăo prévia a cargo do Ministério Público, que ordena e supervisiona a atividade da polícia, e da presença do juiz de controle para as medidas constritivas, estão previstos o princípio da oportunidade, os acordes reparatórios, a suspensão condicional do processo (probation), a etapa intermédia no procedimento ordinário, o procedimento abreviado, o juízo oral. Além disso, tribunais mixtos (escabinato) e de jurados, a intensa participação da vítima e um rico rol de garantías, dentre as quais o contraditório e a defesa técnica desde a fase de investigaçōes. A apelação é mantida, inclusive para matéria de fato, mas é julgada em audiência oral, com comparecimento das partes e produção de prova. A execução é totalmente jurisdiccionalizada.

$\mathrm{Na}$ Bolívia, o código, promulgado em 1999 e com entrada em vigor prevista para $2.001^{15}$, acompanha as linhas do Código Modelo, com a investigação prévia atribuída ao Ministério Público, a previsão de procedimentos abreviados, a adoção de diversos critérios de oportunidades, muitas vezes dependendo da anuência da vítima, a suspensão condicional do processo, uma fase intermédia no procedimento comum,

13 Relator, Rodolfo Duarte Pedro.

14 Mariolga Quintero Tirado.

15 Relator Julio Maier. 
a impugnação da sentença pela cassação tradicional. Não estão contemplados tribunais integrados por jurados.

O Código do $\mathrm{Peru}^{16}$, promulgado em 1991, com prorrogação até o momento da vacatio legiss, só vige, por enquanto, em relação à adoção do princípio da oportunidade. O Código contempla ainvestigação prévia e o exercício da ação penal a cargo do Ministério Público, a reserva das medidas cautelares ao juiz, a intervenção do acusado desde o início da investigação, a legitimação difusa da vítima, procedimentos abreviados, a distinção entre ausência e contumácia, a etapa intermédia no procedimento ordinário.

O projeto do $\mathrm{Chile}^{17}$, aprovado pela Câmara dos Deputados e em fase de revisão no Senado, como entrada em vigor prevista para o ano 2.000, demandou a reforma da Constituição, para nela se incorporar o Ministerio Público, organismo autônomo, que não integra os Poderes tradicionais. A ele estarão entregues as investigaçōes, submetidas a um juiz de garantías para a determinaçáo das medidas restrictivas. Várias soluções do Código Modelo foram adotadas no projeto: o princípio da oportunidade, a suspensão condicional do processo (probation), os acordos reparatórios, a audência correspondente à etapa intermédia. A sentença só poderá fundar-se na prova produzida na etapa do julgamento e o acusado será declarado em audiência «inocente» ou "culpado», com posterior prazo ao colegiado para a redação da sentença. Esta não será impugnável pela via da apelação, mas só pelo recurso de cassação. Discute-se a respeito da introdução de um recurso extraordinário para a revisão de julgados que se tenham apartado da prova produzida. E, finalmente, está previsto o procedimento abreviado para casos de penas limitadas em que haja aceitação dos fatos pelo imputado.

Finalmente, tem-se noticias de que tambén Honduras e Equador promulgaran seus novos Códigos,con ampla inflência do Código Modelo, mas sobre eles e sua entrada em vigor faltam, até o momento, conhecimentos mais seguros ${ }^{18}$.

4.- Em conclusão, pode-se afirmar, 10 anos depois, que o Código Modelo Provocou uma verdadeira revolução no processo penal da América Latina.

16 Relator, Aníbal Quiroga León.

17 Relator, Raul Tavolari.

18 Informacóes de Julio Maier. 
A uma, tornando o sistema acusatório lema e leme das reformas.

A duas, levando sua influência mesmo naqueles países que ainda não conseguiram libertar-se das amarras dos juizados deinstrução, de modo a retirar-lhes as características de instrumento sigiloso de inquisição, abrindo-os ao contraditório.

A três, substituindo-os por uma fase investigativa prévia, destinada exclusivamente à formação da opinio delicti do Ministério Público e cujos resultados não podem servir de base para a condenaçáo, ficando as medidas cautelares reservadas ao juiz.

A quatro, chegando a permear profundamente alguns estatutos processuais, que incorporaram seu modelo.

Diante desse quadro, é lícito esperar que outros países deverão seguir o mesmo exemplo, até chegar o dia em que se poderá efetivamente afirmar a existência de uma plena harmonização o processo penal na América Latina.

Harmonização horizontal, na tipología de Giuseppe Tarzia ${ }^{19}$, que é deixada à iniciativa de cada Estado, num processo que pode ser lento mas resultará mais suave e seguro ${ }^{20}$, no pleno respeito das peculiaridades locais. Processo, esse,que descarta a ideia de unificação, segundo modelos impostos, e que dispensa a harmonização vertical, de índole comunitaria, mas que é profundamente influenciado pela aproximação teórica e pelas experiências comuns.

19 Giuseppe Tarzia, Relatorio Geral apresentado ao XI Congresso Mundial da International Association of Procedural Law (Viena, 23-28 de agosto de 1999), sobre o tema "Une procédure civile sans frontières: harmonization et unification du droit procédural".

20 Roberto Berizonce (Argentina) salientou, no Congresso de Roma, as dificuldades inerentes às mudanças inspiradas no Código Modelo: a mentalidade, a construção de um Ministerio Público autônomo, a implementação das estruturas administrativas. 